\title{
Conhecimento dos profissionais de enfermagem quanto à realização do banho no recém-nascido
}

\section{Knowledge of nursing professionals for the conduct of bath in newborn}

\begin{abstract}
Ylana Laíne Medeiros Lourenço Palhares ${ }^{1}$ Janmilli da Costa Dantas ${ }^{2}$ • Francisca Marta de Lima Costa Souza ${ }^{3}$ Bárbara Coeli Oliveira da Silva ${ }^{4}$ lellen Dantas Campos Verdes Rodrigues ${ }^{5}$. Richardson Augusto Rosendo da Silva ${ }^{6}$
\end{abstract}

RESUMO

Objetivo: Investigar o conhecimento dos técnicos de enfermagem acerca do banho no recém-nascido. Metodologia: Estudo descritivo-exploratório e observacional, com abordagem quantitativa, desenvolvido com 15 técnicos de enfermagem em um hospital universitário na cidade de Santa Cruz-RN. Os dados foram coletados através da observação sistemática e de questionário semiestruturado, analisados através do Excel. A pesquisa foi aprovada pelo Comitê de Ética e Pesquisa (CEP) sob CAAE n 28721814.8.0000.5568. Resultados: 0 conhecimento sobre o banho veio da prática diária. Eles reconhecem a importância do banho para a higienização. Realizam o banho de aspersão e poucos oferecem o banho humanizado. Conclusões: Profissionais necessitam de capacitações direcionadas ao banho humanizado do recém-nascido para sistematizar a sua prática e desenvolver uma assistência.

Palavras-chave: Recém-nascido; Humanização da Assistência; Enfermagem.

\begin{abstract}
Objective: To investigate the knowledge of the nursing staff about the bath in the newborn and the techniques performed by nurses during the course of the bath in the newborn, and apply a checklist for analyzing the assistance while bathing RN. Methodology: An exploratory descriptive and observational study with a quantitative approach, developed with 15 nursing technicians in a university hospital in the city of Santa Cruz-RN. Data were collected through systematic observation and semi-structured questionnaire, analyzed using Excel. The study was approved by the Research Ethics Committee (CEP) under CAAE No 28721814.8.0000.5568. Results: Knowledge of the bath came from daily practice. They recognize the importance of the bath for cleaning. Perform the spray bath and few offer the humanized bath. Conclusions: Professionals require training directed to humanized bath newborn to systematize your practice and develop an assist.
\end{abstract}

Keywords: Newborn; Humanization of Assistance; Nursing.

${ }^{1}$ Enfermeira. Graduada em Enfermagem pela Faculdade de Ciências da Saúde do Trairi - FACISA/UFRN. Santa Cruz/RN, Brasil. E-mail: ylana_laine@hotmail.com.

2 Enfermeira. Mestre em Enfermagem pela Universidade Federal do Rio Grande do Norte - UFRN. Professora do Curso de Graduação em Enfermagem da Faculdade de Ciências da Saúde do Trairi -FACISA/UFRN. Enfermeira Assistencial da Maternidade Municipal Professor Leide Morais. Membro do Grupo de Pesquisa Práticas Assistenciais e Epidemiológicas em Saúde e Enfermagem - PAESE/UFRN. Santa Cruz/RN, Brasil. E-mail: janmilli@yahoo.com.br.

${ }^{3}$ Enfermeira. Mestre em Enfermagem pela Universidade Federal do Rio Grande do Norte - UFRN. Doutoranda do Programa de Pós-Graduação em Enfermagem da Universidade Federal do Rio Grande do Norte/UFRN. Membro do Grupo de Pesquisa Práticas Assistenciais e Epidemiológicas em Saúde e Enfermagem - PAESE/UFRN. Enfermeira Assistencial da Maternidade Municipal Professor Leide Morais. Natal/RN, Brasil. E-mail: enfermarta2001@yahoo.com.br.

${ }^{4}$ Enfermeira. Especialista em Enfermagem em Cardiologia e Hemodinâmica. Mestranda do Programa de Pós-Graduação em Enfermagem pela Universidade Federal do Rio Grande do Norte - UFRN. Professora Substituta do Curso de Graduação em Enfermagem da UFRN. Membro do Grupo de Pesquisa Práticas Assistenciais e Epidemiológicas em Saúde e Enfermagem - PAESE/UFRN. Natal/RN, Brasil. E-mail: barbaracoeli@outlook.com.

${ }^{5}$ Enfermeira. Mestre em Enfermagem pela Universidade Federal do Piauí - UFPI. Doutoranda do Programa de Pós-Graduação em Enfermagem da Universidade Federal do Rio Grande do Norte - UFRN. Membro do Grupo de Pesquisa Práticas Assistenciais e Epidemiológicas em Saúde e Enfermagem - PAESE/UFRN. Natal/RN, Brasil. E-mail: iellendantas@hotmail.com.

${ }^{6}$ Enfermeiro. Doutor em Ciências da Saúde. Professor do Curso de Graduação e do Programa de Pós-Graduação (Mestrado Acadêmico e Doutorado) em Enfermagem da Universidade Federal do Rio Grande do Norte/UFRN. Natal/RN, Brasil. Vice-líder do Grupo de Pesquisa Práticas Assistenciais e Epidemiológicas em Saúde e Enfermagem PAESE/UFRN.E-mail: rirosendo@hotmail.com. 


\section{INTRODUÇÃO}

O recém-nascido $(\mathrm{RN})$, após o seu nascimento, necessita de cuidados essenciais para a manutenção da saúde. A adaptação do $\mathrm{RN}$ ao meio extrauterino é um processo fisiológico, representa uma das fases mais dinâmicas e difíceis do ciclo vital humano que exige a transformação de uma condição de completa dependência durante a vida intrauterina dentro da placenta, para outra de autossuficiência em relação à oxigenação e nutrição, o meio extrauterino ${ }^{1-2}$. Após o nascimento, os RN's são considerados vulneráveis e possuem instabilidade em suas condições de vitalidade ${ }^{1}$. Por isso, os cuidados prestados ao RN imediatamente após o parto pelos profissionais de saúde são fundamentais para a adaptação sua ao meio extrauterino.

Durante a internação na maternidade, o RN é colocado junto à mãe, onde permanece até a alta hospitalar no Alojamento Conjunto (AC). O AC é um ambiente caracterizado com alto teor educativo, pois nele devem ocorrer orientações rotineiras às mães e aos familiares sobre vários aspectos relacionados aos cuidados seguros do $\mathrm{RN}$, orientações essas a respeito do aleitamento materno, uso de mamadeiras e chupetas, posição em que o RN deve dormir, interação com o RN, controle das eliminações, cuidados com o coto umbilical, a troca de fraldas e o banho do $\mathrm{RN}^{3}$. Sendo assim, para que as puérperas apreendam todos os cuidados necessários para a manutenção da saúde do RN, é fundamental a formação de vínculos e de uma assistência integral no AC.

A equipe de enfermagem deve envolver os pais durante esse cuidado para fortalecer e aprimorar os laços afetivos durante o banho do RN. Os profissionais não devem apenas explanar como deve ser feito o banho no $\mathrm{RN}$, mas fazê-lo, instruindo e mostrando a sua importância, os benefícios, como a família pode aprimorar essa prática em casa, e, principalmente, acompanhar o primeiro banho da puérpera no seu RN.

O banho é caracterizado por um excesso de manipulação do bebê, no qual favorece um vínculo entre o binômio mãefilho. O banho pode produzir diversas reações no recémnascido, como fazer uma breve nostalgia do ambiente líquido e quente característico do útero materno ${ }^{4}$.

Após o seu nascimento, o recém-nascido vive mudanças distintas do ambiente intrauterino, onde muitos RN's, até a sua adaptação, ficam irritados e chorosos. Sendo assim, através do banho, podemos proporcionar um momento calmo, relaxado, tranquilo e agradável, fazendo o $\mathrm{RN}$ relembrar o ambiente intrauterino ${ }^{5}$. Portanto, o momento do banho deve ser um momento prazeroso para o bebê, para que ele se sinta bem ${ }^{6}$.

É preciso enfatizar, então, que o banho do RN, para as puérperas, vai muito além das medidas de higiene, uma vez que precisa ser terapêutico para o recém-nascido. Portanto, os profissionais devem estar qualificados para atuarem na educação e na execução do banho humanizado, oferecendo ao RN e a sua família uma assistência integral e de qualidade.

$\mathrm{O}$ interesse pela realização dessa pesquisa partiu da vivência de aulas práticas em Alojamento Conjunto na disciplina de Atenção Integral à Saúde na Média Complexidade em um hospital maternidade universitário, onde observou- se que o primeiro banho era realizado pelos técnicos de enfermagem. Assim, surgiu o seguinte questionamento: Quais os conhecimentos desses profissionais de enfermagem acerca do banho no recém-nascido?

Dessa forma, elaborou-se a seguinte questão de pesquisa: os profissionais que realizam o banho no recém-nascido possuem conhecimentos técnicos e científicos para a realização do banho, obtidos através de atualizações e treinamentos no serviço?

Espera-se que esta pesquisa propicie uma melhor compreensão a respeito do conhecimento dos profissionais de enfermagem sobre o banho no $\mathrm{RN}$ e que possa subsidiar a prática desses profissionais em uma assistência humanizada, integral e de qualidade durante o banho do RN. Além disso, pretende-se contribuir na melhoria das práticas assistenciais, refletindo nos cuidados prestados ao binômio mãe-filho, reduzindo seus anseios e medos e aumentando o vínculo. A pesquisa também contribuirá para o aumento do conhecimento do meio científico, uma vez que existem poucos estudos abordando essa temática.

Em meio a essa problemática, o presente estudo objetivou investigar o conhecimento dos técnicos de enfermagem acerca do banho no recém-nascido.

\section{METODOLOGIA}

A pesquisa é do tipo descritiva-exploratória e observacional, com abordagem quantitativa. Desenvolvida no hospital universitário localizado na cidade de Santa Cruz, interior do Rio Grande do Norte. O hospital é referência em assistência materno-infantil na região, atendendo exclusivamente pelo SUS e possui o título de hospital Amigo da Criança.

A população do estudo foi composta por todos os técnicos de enfermagem que faziam parte da escala do Alojamento Conjunto (AC) e Pré-Parto, Parto e Pós-Parto (PPP), já que, nesse hospital, são eles os responsáveis pela realização do banho no RN. Atuam nesses setores 17 técnicos de enfermagem. Um profissional não realiza o banho e outro estava afastado de suas atividades laborais no período das coletas de dados. Assim, participaram do estudo 15 profissionais.

Os critérios de inclusão para participar da pesquisa foram: fazer parte da escala do AC ou PPP, realizar o banho do RN e assinar o Termo de Consentimento Livre e Esclarecido (TCLE). E o método de exclusão constituiu em profissionais que, apesar de fazerem parte da escala do AC ou PPP, não realizam o banho no RN.

Antes de iniciar a coleta de dados, foi feita a testagem do instrumento com 05 profissionais com a finalidade de avaliar a sua aplicabilidade e coerência com os objetivos do estudo. Foram acrescentadas duas perguntas no instrumento: Quais as mudanças sugeridas para a sala do banho? E qual o tempo esperado entre o nascimento da criança e a realização do primeiro banho? 
A coleta de dados foi realizada entre os meses de maio e agosto de 2014, e dividida em duas partes: na primeira fase, foi utilizado o método da observação sistemática durante os banhos do RN; na segunda fase, foi aplicado um questionário semiestruturado.

A primeira etapa do estudo foi realizada na sala do banho no $\mathrm{AC}$ durante o primeiro banho do $\mathrm{RN}$, onde foi utilizado um check-list preenchido pelo pesquisador, enquanto observava a realização do banho pelo técnico em enfermagem. Durante essa etapa, foi mantida uma distância considerável dos profissionais a fim de não haver nenhum tipo de influência durante os banhos dos neonatos. Esse check-list foi construído pela pesquisadora do estudo baseado no livro "Enfermagem Neonatal cuidado integral ao recém-nascido". Pelas literaturas consultadas, esse autor apresentou um protocolo mais abrangente para a realização do banho.

A segunda fase do estudo foi realizada individualmente, em uma sala reservada na instituição. Nessa fase, o profissional respondeu ao questionário dividido em duas partes. A primeira abordava a caracterização dos participantes do estudo; na segunda parte, as perguntas eram direcionadas aos objetivos da pesquisa. Após o encerramento da coleta de dados, os participantes receberam um folder educativo confeccionado pelos pesquisadores do estudo contendo informações sobre a realização do banho no recém-nascido.

Os dados foram digitados no Excel. As respostas das questões abertas foram categorizadas e agrupadas. Em seguida, realizamos a estatística descritiva com frequências absolutas e percentuais.

Sobre os preceitos éticos, o presente estudo está fundamentado na Resolução 466/2012 do Conselho Nacional de Saúde ${ }^{8}$. A pesquisa foi autorizada pela direção de pesquisa do hospital e aprovada pelo Comitê de Ética e Pesquisa (CEP) da Faculdade de Ciências da Saúde do Trairí (FACISA), da Universidade Federal do Rio Grande do Norte (UFRN), sob CAAE $n^{\circ}$ 28721814.8.0000.5568. Todos os participantes assinaram o TCLE.

\section{RESULTADOS}

A população estudada foi composta por 15 técnicos de enfermagem com idade mínima de 26 anos e máxima de 60 anos, com média de 48 anos; 46,7\% ( $n=7)$ estavam no intervalo etário entre 46 a 55 anos; 66,7\% (n=10) eram do sexo feminino; $40 \%(n=6)$ eram casados; e $60 \%(n=9)$ com a maior escolaridade de nível técnico. Em relação ao tempo de exercício da profissão de técnico de enfermagem, compreendeu um intervalo entre dois e trinta e seis anos, no qual, $46,7 \%(n=7)$ exercem a profissão de técnico de enfermagem há mais de 30 anos com a média de tempo profissional de 23,5 anos. Já em relação ao tempo em que trabalham com assistência ao recém-nascido, predominou um intervalo de três meses a trinta e seis anos, no qual, $40 \%(n=6)$ trabalham na assistência ao recém-nascido a menos de um ano e $33,3 \%(n=5)$ assistem o RN há mais de 10 anos. Observou-se, também, que 93,3\% ( $n=14$ ) dos profissionais não receberam nenhuma capacitação oferecida pela instituição sobre o banho, antes ou durante o exercício de suas atividades na instituição, mas alegaram capacitações sobre Aleitamento Materno Exclusivo (AME), assistência ao RN no berçário patológico, urgência e emergência, UTI-neo e HIV.

Durante a coleta, foi questionado sobre qual o conhecimento dos profissionais a respeito da importância do banho para o RN, na qual, observou-se que $73,3 \%$ (n=11) dos participantes da pesquisa elencaram o banho do RN como fundamental para a higiene do bebê (figura 1).

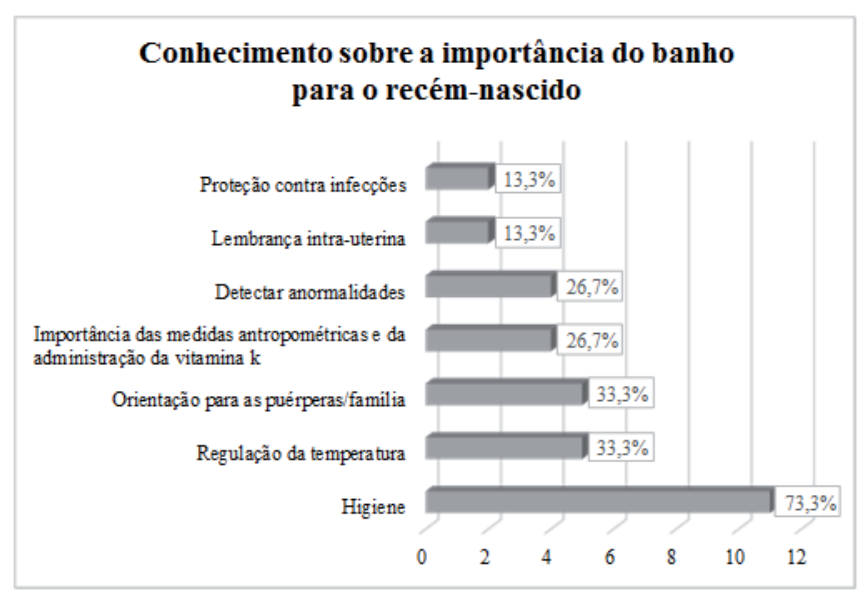

Figura 1. Conhecimento dos profissionais sobre a importância do banho para o recém-nascido. Santa Cruz, RN, Brasil, 2014.

No que se refere ao banho humanizado, $86,7 \%(n=13)$ dos profissionais referiram que conseguem oferecer esse tipo de banho, em que utilizam estas ferramentas técnicas para realizá-lo: água morna, orientações para a puérperas e familiares sobre o coto umbilical, forma adequada de manusear o RN durante o banho, dentre outros itens (figura 2). Entretanto, $13,3 \%(n=2)$ dos profissionais referiram que não conseguem oferecer o banho humanizado devido à sobrecarga de trabalho associada à falta de tempo, problemas na estrutura física e de materiais e a falta de rotina do banho humanizado na instituição. Vale ressaltar que alguns profissionais responderam mais de uma categoria, o que justifica a somatória das categorias da figura ser superior a $100 \%$.

Em se tratando das dificuldades em que os profissionais tinham durante a assistência no banho do RN, observouse que $53,3 \%(n=8)$ dos profissionais referiram que não apresentavam dificuldades em relação ao banho, já os demais profissionais referiram ter dificuldade durante 0 manuseio do RN, além de outras dificuldades como: setor desorganizado, equipamentos desapropriados e o medo que os assolam durante essa prática.

Durante a observação sistemática foi aplicado o checklist no qual foi observado de forma detalhada o passo a passo durante o banho, envolvendo as etapas desde o preparo para o banho até após o banho (tabela 1). 


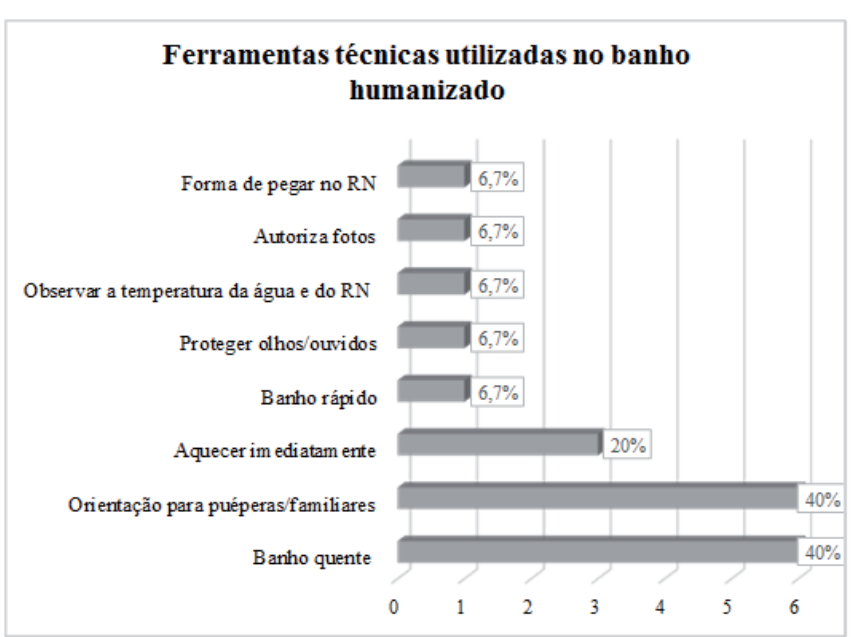

Figura 2. Ferramentas técnicas utilizadas pelos profissionais durante a realização do banho humanizado no RN. Santa Cruz, RN, Brasil, 2014.

Fonte: Dados da pesquisa.

\section{DISCUSSÃO}

Os dados expressos trazem a realidade da assistência e dos conhecimentos dos profissionais de enfermagem sobre a realização do banho no RN naquela instituição. Nas características dos profissionais, destacou-se profissionais com formação técnica antiga e com tempo de experiência entre três meses e trinta e seis anos no cuidado ao RN, em que a grande maioria desses profissionais não receberam capacitação pela instituição sobre o banho antes de ser lotado no setor. $O$ fato de haver um percentual considerável na assistência ao RN há menos de 1 ano, é justificável, visto que a instituição está passando por processos de reformas que estão influenciando influenciou em algumas atividades dos profissionais que atuam no PPP como, por exemplo, com o cuidado ao recém-nascido.

Os participantes da pesquisa enfatizaram que tudo que conhecem sobre o banho foi adquirido durante as práticas diárias, por ser mãe, por ter adquirido conhecimentos em outros hospitais que trabalharam e orientação no setor por outros profissionais mais antigos.

No campo da área da saúde, há uma necessidade constante de atualização do conhecimento dos profissionais, frente às mudanças tecnológicas de nosso tempo, pois os conhecimentos e saberes tecnológicos se renovam na área da saúde 9 . As atualizações dos profissionais permitem beneficiar tanto os trabalhadores como os usuários dos serviços, melhorando, assim, a qualidade da assistência oferecida pela instituição.

No que se refere ao ambiente de AC, é imprescindível que os profissionais de saúde que assistem os RN's e as famílias desses bebês sejam capacitados e atualizados para atendê-los de forma integral, humanizada e com qualidade.

De acordo com o Ministério da Saúde, o primeiro banho dos bebês, a termo, pode ser considerado como algo
Tabela 1. Check-list preenchido durante a assistência de enfermagem no banho do RN. Santa Cruz, RN, Brasil, 2014.

\begin{tabular}{|c|c|c|c|c|}
\hline \multirow{2}{*}{ Variáveis } & \multicolumn{2}{|c|}{ Sim } & \multicolumn{2}{|c|}{ Não } \\
\hline & $\mathbf{N}$ & $\%$ & $\mathbf{N}$ & $\%$ \\
\hline \multicolumn{5}{|l|}{ Preparo antes do banho } \\
\hline 1.Preparação prévia do material & 12 & 80 & 3 & 20 \\
\hline 2.Verificou a temperatura do $\mathrm{RN}$ & 0 & 0 & 15 & 100 \\
\hline $\begin{array}{l}\text { 3.Realizou higienização dos } \\
\text { utensílios de uso coletivo }\end{array}$ & 0 & 0 & 15 & 100 \\
\hline $\begin{array}{l}\text { 4.Colocou toalha seca no local onde } \\
\text { será realizado a troca da criança }\end{array}$ & 15 & 100 & 0 & 0 \\
\hline 5. Colocou avental & 5 & 33,3 & 10 & 6,7 \\
\hline 6. Colocou luva de procedimento & 15 & 100 & 0 & 0 \\
\hline 7. Verificou temperatura da água & 11 & 73,3 & 4 & 26,7 \\
\hline $\begin{array}{l}\text { 8. Esperou completar duas horas de } \\
\text { vida }\end{array}$ & 5 & 33,3 & 10 & 66,7 \\
\hline \multicolumn{5}{|l|}{ Preparo durante o banho } \\
\hline $\begin{array}{l}\text { 9. Iniciou pela higiene do rosto, } \\
\text { limpando os olhos do canto interno } \\
\text { para o externo }\end{array}$ & 3 & 20 & 12 & 80 \\
\hline $\begin{array}{l}\text { 10. Na limpeza do rosto e cabeça o } \\
\text { RN mantém-se coberto para ajudar } \\
\text { a reduzir a perda de calor }\end{array}$ & 3 & 20 & 12 & 80 \\
\hline $\begin{array}{l}\text { 11. Para lavar a cabeça: apoiou } \\
\text { o corpo do neonato sob a região } \\
\text { axilar, segurando com uma das } \\
\text { mãos }\end{array}$ & 5 & 33,3 & 10 & 66,7 \\
\hline $\begin{array}{l}\text { 12. Protegeu o meato auricular com } \\
\text { o dedo anelar e polegar }\end{array}$ & 3 & 20 & 12 & 80 \\
\hline $\begin{array}{l}\text { 13. Na lavagem da cabeça } \\
\text { massageou o couro cabeludo de } \\
\text { forma delicada }\end{array}$ & 15 & 100 & 0 & 0 \\
\hline $\begin{array}{l}\text { 14. Segurou o RN com firmeza: } \\
\text { antebraço esquerdo apoiando a } \\
\text { cabeça do RN e a mão esquerda } \\
\text { segurando o braço esquerdo do RN }\end{array}$ & 15 & 100 & 0 & 0 \\
\hline $\begin{array}{l}\text { 15. Girou o RN de modo que o } \\
\text { braço esquerdo passa apoiar o peito } \\
\text { e o rosto do RN }\end{array}$ & 15 & 100 & 0 & 0 \\
\hline $\begin{array}{l}\text { 16. Iniciou o banhou familiarizando } \\
\text { o RN com a temperatura da água }\end{array}$ & 8 & 53,3 & 7 & 46,7 \\
\hline
\end{tabular}

\section{Cuidados pós-banho}

17. Utilizou algum método para massagear o RN, com finalidade de tranquiliza-lo

18. A família foi convidada a participar do momento do banho com intuito na formação de vínculos

19. Houve orientação para a família durante o banho

20. Houve interação com o RN durante o banho

21. Secou cuidadosamente o RN

22. Realizou a higiene do coto umbilical corretamente

23. Verificou as medidas

antropométricas (PC, PT, PA, estatura

e peso) e a administração da

vitamina $\mathrm{K}$

\begin{tabular}{|c|c|c|c}
\hline 10 & 66,7 & 5 & 33,3 \\
\hline 7 & 46,7 & 8 & 53,3 \\
\hline 5 & 33,3 & 10 & 66,7 \\
\hline 10 & 66,7 & 5 & 33,3 \\
\hline 15 & 100 & 0 & 0 \\
\hline 13 & 86,7 & 2 & 13,3 \\
\hline 15 & 100 & 0 & 0 \\
\hline
\end{tabular}

Fonte: Dados da pesquisa. 
prazeroso, pois deve lembrar o ambiente líquido e quente característico do útero materno ${ }^{10}$.

0 primeiro banho no recém-nascido tem finalidade inicial de reduzir a colonização microbiana, remover as secreções maternas, evitando riscos ao $\mathrm{RN}$ e seus cuidadores a possíveis agentes transmissores de doenças como hepatite $B$, herpes simples e HIV, além de envolver questões estéticas, culturais e expectativas da família ${ }^{1}$.

Em um estudo, constatou-se que o banho humanizado no RN traz diversos benefícios, pois proporciona uma melhor resposta adaptativa ao ambiente, promove organização dos sistemas comportamentais, motores, fisiológicos e de interação ao meio, diminui o gasto de energia durante o banho e contribui positivamente para o desenvolvimento sadio ${ }^{11}$.

De acordo com a figura 1, os participantes da pesquisa relataram o primeiro banho do RN como fundamental para a higienização com intuito de retirar as secreções e sangue proveniente do parto, para evitar quadros infecciosos nos neonatos. Além disso, é no primeiro banho que são realizados os primeiros cuidados com o RN: administração da vitamina $K$, verificação dos dados antropométricos (peso, comprimento, perímetro cefálio, perímetro torácico, perímetro abdominal) e a assepsia do coto umbilical.

De fato, a finalidade do banho, inicialmente, é reduzir a colonização microbiana, remover as secreções maternas para evitar riscos ao RN e seus cuidadores, entretanto, o banho deve ir além dessa finalidade inicial. Através do banho, com a estimulação tátil e da circulação geral da pele, pode-se proporcionar um momento calmo, relaxado, tranquilo e agradável, fazendo com que o $\mathrm{RN}$ relembre o ambiente intrauterino, contribuindo para sua adaptação à vida extrauterina ${ }^{10}$. Todavia, essa percepção foi pouco destacada durante a coleta de dados, pois um quantitativo pequeno dos profissionais verbalizou o banho além do caráter de higienização.

As técnicas tradicionais para o banho são: banho de imersão e banho de aspersão: no primeiro tipo de banho, o RN é colocado despido em uma banheira ou bacia com água; já no segundo, é utilizado um chuveiro ou torneira para a auxiliar no banho. Entretanto, ambos os banhos têm o intuito da promoção da higiene. Todavia, atualmente, existem banhos que, além do caráter de higienização, trazem benefícios para os bebês e pais, conhecidos como banhos humanizados, denominados: banho japonês e banho de ofurô. Em ambas as técnicas, o RN não se sentirá inseguro e relembrará o útero materno ${ }^{6}$.

Sendo assim, percebe-se que o banho tradicional é mais técnico, pois seu objetivo é apenas a higienização. Já o banho humanizado, além da higienização, privilegia um cuidado humanizado, proporciona um cuidado menos estressante e mais prazeroso para o RN, e ainda aumenta a afetividade entre o familiar e o neonato, possibilitando maior conforto e acolhimento.

Durante a observação sistemática foi visualizado que todos os banhos realizados foram de aspersão. A estrutura física do local direciona para essa prática. Assim, uma melhoria nessa estrutura e uma melhor organização nos materiais necessários, além de treinamento e incentivo aos profissionais poderia vir a melhorar a técnica do banho naquela instituição. Entretanto, três profissionais adaptaram o banho japonês no banho de aspersão, de forma que envolveram o RN com o pano/fralda ao iniciar a higienização pelo rosto, a fim de tentar oferecer uma melhor assistência durante o momento do banho de acordo com os recursos disponíveis na instituição. Um dos participantes da pesquisa mencionou o banho do balde (ofurô) e conhecia as vantagens em relação ao relaxamento do RN. A instituição disponibiliza o balde, contudo, o participante referiu ter realizado apenas duas vezes, por achar a técnica do banho de ofurô difícil.

Ressalta-se que todos os profissionais executaram técnicas importantes no banho do RN, como: o uso das luvas de procedimentos, seguraram o RN de forma delicada e secaram o RN vagorosamente.

No que diz respeito ao banho humanizado, $86,7 \%$ $(n=13)$ dos profissionais referiram que conseguem oferecer esse tipo de banho. Entretanto, de acordo com os dados obtidos no questionário e a observação sistemática, ficou perceptível que a maioria não conseguia, de fato, oferecelo. Apenas $20 \%(n=3)$ dos profissionais ofereceram o banho humanizado, não coincidindo com os dados do questionário.

Ao questionar as ferramentas técnicas que utilizavam para realizar um banho humanizado, mencionaram: banho quente, trazer familiares para próximo do banho para fazer orientações pertinentes ao banho e a higienização do coto umbilical, não demorar muito durante o banho para o RN não perder calorias e aquecer imediatamente após o banho, proteger os olhos e ouvidos e observar a temperatura da água e do bebê.

De fato, todos os itens mencionados por eles são utilizados no banho humanizado, contudo, esses itens também devem ser utilizados no banho técnico que tem caráter apenas de higienização.

As dificuldades apontadas pelos profissionais para a realização do banho foram: manuseio da criança, setor desorganizado, medo e equipamentos desapropriados (pia). Além dessas dificuldades, dois profissionais relataram que não conseguiriam oferecer o banho humanizado devido à falta de dimensionamento de profissionais no setor, uma grande demanda de atividades para poucos profissionais, além de não ser rotina do serviço.

Os dados corroboram com um estudo em que os profissionais de enfermagem elencaram como desvantagem do AC para desempenhar as suas funções: número reduzido de funcionários, instalações físicas inadequadas, falta de materiais e tempo disponíveis para realização das atividades ${ }^{12}$. Sendo assim, percebe-se que essas dificuldades encontradas pelos profissionais podem gerar sentimentos negativos que podem influenciar tanto na qualidade de vida do profissional, como na qualidade da assistência ao usuário do serviço. 
Os técnicos de enfermagem sugeriram mudanças na sala do banho para melhor oferecer assistência ao RN durante esse cuidado, dentre as quais: ambiente fechado mais privativo, higienização/desinfecção dos utensílios de uso coletivo entre os banhos dos RN's, obrigação do uso de todos os Equipamentos de Proteção Individual (EPI's), mudanças no espaço físico, na pia e nos depósitos de álcool e sabonete, colocar um armário para organizar o setor, troca de luva após o banho para a higienização do coto, e chuveiro elétrico com regulação adequada para a temperatura da água. Ressaltamos que o setor possui álcool a $70 \%$ e sabonete líquido que poderiam ser utilizados na desinfecção dos materiais. Acredita-se que a falta de rotina na instituição os levam a não realizarem essa desinfecção.

Durante a observação sistemática, no preparo antes do banho, notou-se que $33,3 \% \quad(n=5)$ dos profissionais aguardaram duas horas após o nascimento para a realização do primeiro banho.

Atualmente, o momento ideal para o primeiro banho no RN ainda é controverso na literatura. $O$ primeiro banho do $\mathrm{RN}$ tem sido realizado cada vez mais cedo com intuito de reduzir a possibilidade da transmissão de patógenos através do sangue e das secreções corporais do RN com potencial de contaminar tanto profissionais de saúde como familiares, justificando, assim, a ideia de muitas instituições a dar o banho nas primeiras horas após o nascimento ${ }^{13}$.

No entanto, a Organização Mundial de Saúde (OMS), recomenda que o primeiro banho seja realizado apenas seis horas após o parto, devido ao risco de hipotermia durante e após o banho ${ }^{14}$. Já outro estudo considera que o primeiro banho deve ser dado apenas quando a temperatura do RN estiver estável e não estar relacionado ao número de horas após o nascimento ${ }^{15}$.

Sendo assim, ao se fazer a opção de executar o banho, o profissional deve estar atento aos fatores de termoregulação e sinais vitais do RN para não ocasionar um estresse térmico e grandes perdas de calorias nos neonatos. Entretanto, nenhum dos profissionais verificou a temperatura do RN em algum momento antes do banho. Durante a aplicação do questionário, ainda foi interrogado sobre o quesito da temperatura, todavia, os profissionais alegaram não ser prática da instituição.

A higienização dos utensílios de uso coletivo também não foi realizada por nenhum dos profissionais. As higienizações dos utensílios e equipamentos devem ser realizadas, pois os mesmos podem se tornar fômites passíveis de transmissão para outros neonatos.

Outro item importante no preparo antes do banho foi o uso do avental, pois, apenas $33,3 \%(n=5)$ dos profissionais fizeram o uso desse EPI. Os profissionais apontam como importante o uso dos EPI's e até colocam como fundamental a obrigação do mesmo durante o procedimento. A instituição disponibiliza-os, contudo, nem todos fazem o uso. Vale destacar que em relação ao uso das luvas de procedimentos, $100 \%(n=15)$ dos profissionais fizeram o uso.
Durante o banho propriamente dito, apenas 20\% $(n=3)$ dos profissionais iniciaram a higiene pelo rosto e, enquanto faziam a higienização do rosto e da cabeça, o RN era mantido coberto para ajudar a reduzir o calor.

Outro ponto importante de ser mencionado é a proteção do meato auricular que apenas $20 \%(n=3)$ dos profissionais o realizaram.

Uma questão importante a destacar é que, na sala do banho, existe um fluxograma do passo a passo do banho humanizado, que foi produzido por discentes do curso enfermagem da FACISA/UFRN, o qual explica de forma detalhada como fazê-lo. Mas, mesmo assim, $80 \%(n=12)$ dos profissionais não o realizaram, e os três profissionais que realizaram destacaram a importância daquele fluxograma durante a prática do banho.

Nos cuidados pós-banho, os profissionais que convidaram as puérperas e/ou familiares realizaram orientações apenas direcionadas à higienização do coto umbilical. As orientações direcionadas ao manuseio e cuidados com o banho no RN não foram enfatizados. Fato este que nos levanta preocupação, uma vez que as puérperas/familiares têm receio em oferecer o primeiro banho e necessitam ser melhor orientados e encorajados. Alguns profissionais não realizaram nenhum tipo de orientação e outros nem convidaram a mãe a participar desse momento do banho.

O AC é um espaço facilitador para o cuidado materno e favorecimento de vínculo mãe-bebê. Sendo assim, o banho é um momento ideal para realizar orientações sobre diversos cuidados ao RN. Os profissionais que atuam na assistência materno-infantil devem sanar todas as dúvidas das puérperas/família sobre o puerpério e cuidado ao RN até a alta hospitalar.

\section{CONCLUSÕES}

A partir da análise dos dados e considerando os objetivos propostos nesse estudo, observou-se que, para os participantes da pesquisa, o primeiro banho do recémnascido está restrito apenas ao caráter higiênico a fim de reduzir a colonização microbiana e remover as secreções maternas, evitando riscos ao $\mathrm{RN}$ e seus cuidadores. Poucos profissionais conheciam e/ou ofereciam o banho humanizado. 0 conhecimento desses profissionais em relação ao banho foi adquirido através das vivências diárias, por ser mãe ou por ter trabalhado em outros hospitais na assistência do $\mathrm{RN}$, e não através de treinamento/ atualizações.

O momento do banho é uma ocasião ideal para esclarecer dúvidas e reduzir os medos e anseios das puérperas e familiares sobre os primeiros cuidados, sendo assim, foram observadas que as orientações realizadas pelos profissionais durante a assistência do banho estavam voltadas para o cuidado com o coto umbilical, não incluindo as orientações do banho. 
Diante disso, propõem-se capacitação dos profissionais sobre o banho humanizado a fim de embasar e sistematizar a prática desses profissionais em uma assistência humanizada, integral e de qualidade durante o banho do RN.

Foi sinalizado para que o hospital insira, na sua política de humanização do cuidado ao recém-nascido, a realização do banho humanizado.

Sugere-se novas pesquisas que abordem a elaboração e validação de um protocolo de enfermagem para a realização do banho no recém-nascido como forma de sistematizar essa prática e garantir uma assistência embasada em conhecimentos científicos.

\section{REFERÊNCIAS}

1. Muller EB. Cuidados ao recém-nascido no Centro Obstétrico: uma proposta de enfermeiras com base nas boas práticas. [Dissertação de Mestrado]. Florianópolis: Universidade Federal de Santa Catarina; 2012.

2. Lara SHO, Goulart MJP, Carmo TMD. Assistência ao recémnascido pelos profissionais de enfermagem na sala de parto no momento da recepção. Cienc. Prax. [Internet]. 2010 [acesso 10 set 2014]; 3(5): 35-42. Disponível em: http://www.fespmg. edu.br/books/Revista-Ciencia-Et-Praxis/Volume-03-N-05Janeiro-Junho-2010/files/assets/basic-html/page39.html.

3. Brasil. Atenção humanizada ao recém-nascido de baixo peso: Método Canguru. 2. ed. Brasília: Editora do Ministério da Saúde; 2011. 204p.

4. Perini C, Seixas MC, Catão ACSM, Silva GD, Almeida VS, Matos PBCM. Banho de ofurô em recém-nascidos no alojamento conjunto: um relato de experiência. J. res.: fundam. care. [online] 2014 [acesso 01 jul 2016];6(2):785-792 785. Disponível em: http://www.seer.unirio.br/index.php/cuidadofundamental/article/ view/2851

5. Feyer ISS, Burigo RA. O florescer da vida: parto domiciliar planejado, orientações para gestantes, parto e pós-parto. Florianópolis: Lagoa Editora; 2009.

6. Hemkeimeir J, Fermino VC, Ribeiro IM. Percepção de familiares referente ao banho humanizado: técnica japonesa em recémnascidos. Rev. Cienc. Saúde. [Internet]. 2012 [acesso 10 set 2014]; 5(1): 2-8. Disponível em: http://revistaseletronicas. pucrs.br/ojs/index.php/faenfi/article/view/9135/7741.

7. Souza ABG. Enfermagem Neonatal cuidado integral ao recémnascido. São Paulo: Martinari; 2011.

8. Brasil. Ministério da Saúde. Conselho Nacional de Saúde. Resolução 466, de 12 de dezembro de 2012: diretrizes e normas regulamentadoras de pesquisa envolvendo seres humanos. Brasília; 2012.

9. Morais Filho, LA, Marinho CSR, Backes VMS, Martini JG. Educação permanente em saúde: uma estratégia para articular ensino e serviço. Rev. Rene. [Internet]. 2013 [acesso 10 set 2014]; 14(5): 1050-60. Disponível em: http://www.revistarene. ufc.br/revista/index.php/revista/article/view/102/pdf_1.

10. Brasil. Atenção à saúde do recém-nascido: guia para os profissionais de saúde. 2. ed. Brasília: Ministério da Saúde; 2012.
11. Medeiros JS, Mascarenhas MFPT. Banho humanizado em recém-nascido prematuros de baixo peso em uma enfermaria canguro. Rev. Ter. Ocup. Univ. São Paulo. [Internet]. 2010 [acesso 10 set 2014]; 21(1): 51-60. Disponível em: http:// www.revistas.usp.br/rto/article/viewFile/14085/15903.

12. Faria AC, Magalhães L, Zerbetto SR. Implementação do alojamento conjunto: dificuldades enfrentadas na percepção de uma equipe de enfermagem. Rev. Eletr. Enf. [Internet]. 2010 [acesso 10 set 2014]; 12(4): 669-77. Disponível em: https:// www.fen.ufg.br/fen_revista/v12/n4/v12n4a11.htm.

13. Pugliesi VEM, Deutsch D’A, Freitas M, Dornaus MFPS, Rebellos CM. Efeitos do banho logo após o nascimento sobre as adaptações térmica e cardiorrespiratória do recém-nascido a termo. Rev. Paul. Pediatr. [Internet]. 2009 [acesso 10 set 2014]; 27(4): 410-415. Disponível em: http://www.scielo.br/pdf/rpp/ v27n4/v27n4a10.pdf.

14. Fernandes JD, Machado MCR, Oliveira ZNP. Prevenção e cuidado com a pele do recém-nascido. An Bras Dermatol. [Internet]. 2011 [acesso 10 set 2014]; 86(1): 102-10. Disponível em: http://www.scielo.br/pdf/abd/v86n1/v86n1a14.pdf.

15. Blume-Peytavi U, Cork MJ, Faergemann J, Szczapa J, Vanaclocha F, Gelmetti C. Bathing and cleansing in newborns from day 1 to first year of life: recommendations from a European round table meeting. J. Eur. Acad. Dermatol.Venereol. [Internet]. 2009 [acesso 10 set 2014]; 23 (7): 751-9. Disponível em: http:// www.ncbi.nlm.nih.gov/pubmed/19646134. 